patients who had had meconium ileus equivalent did not have less well controlled steatorrhoea than those who had not had meconium ileus equivalent, and neither prophylactic treatment nor newer pancreatic enzyme supplements has reduced the incidence of meconium ileus equivalent.

The failure of prophylaxis necessitates adequate treatment to relieve attacks. Surgery is hazardous and should be avoided wherever possible. ${ }^{3}$ Currently described regimens of medical management ${ }^{34}$ are effective but unpleasant and require admission to hospital.

Gastrografin is a radiological contrast medium, containing sodium diatrizoate $100 \mathrm{mg} / \mathrm{ml}$, meglumine diatrizoate $660 \mathrm{mg} / \mathrm{ml}$, and iodine $370 \mathrm{mg} / \mathrm{ml}$, plus flavouring and wetting agents. It is hypertonic with an osmolality of $2150 \mathrm{MOsm} / \mathrm{kg} \mathrm{H}_{2} \mathrm{O}$ at $37^{\circ} \mathrm{C}$. Absorption from the intestine is minimal.

When Gastrografin is given by enema to relieve obstruction in the newborn, or in older patients with cystic fibrosis with meconium ileus equivalent, the manufacturers recommend that it be diluted fourfold with water. In our hospital children who require Gastrografin enemas to relieve meconium ileus equivalent have been given $100-200 \mathrm{ml}$ Gastrografin in three times that volume of water, under fluoroscopic control.

We have found smaller oral doses, $50 \mathrm{ml}$ in children under 8 years and $100 \mathrm{ml}$ in those 8 years and older, to be effective. All children drink at least four times that volume of water or fruit squash with the Gastrografin. None of our patients has developed dehydration after these doses of Gastrografin, and electrolytes measured in inpatients were normal.

Oral Gastrografin is contraindicated where there is pre-existing dehydration, prolonged obstruction, or evidence of acute abdomen or iodine sensitivity but may otherwise safely be given to children aged over 5 years as outpatients.

Oral Gastrografin is a simple, safe, and effective outpatient treatment. We consider it to be the treatment of choice in acute meconium ileus equivalent in cystic fibrosis.

\footnotetext{
References

${ }^{1}$ Hodson ME, Norman AP, Batten JC. Cystic fibrosis. London: Bailliere Tindall, 1983:153-7.

2 Lloyd Still JD. Textbook of cystic fibrosis. Boston: John Wright PSG, 1983:159-61, 360-1.

${ }^{3}$ Hodson ME, Mearns MB, Batten JC. Meconium ileus equivalent in adults with cystic fibrosis of the pancreas. $\mathrm{Br}$ Med $\mathrm{J}$ 1976;ii:790-1.

${ }^{4}$ Pilling DW, Steiner GM. The radiology of meconium ileus equivalent. $\mathrm{Br} J$ Radiol 1981;50:562-5.
}

Correspondence to Dr D P Heaf, Respiratory Unit, Alder Hey Children's Hospital, Eaton Road, Liverpool L12 2AP, England.

Received 6 June 1986

\title{
Spontaneous subhyaloid and retinal haemorrhages in an infant
}

\author{
N J MCLELLAN, R PRASAD, AND J PUNT \\ Departments of Child Health and Paediatric Neurosurgery, University Hospital, Queen's Medical Centre, \\ Nottingham
}

SUMMARY A 6 week old girl from a socially isolated family presented with seizures and was found to have a full fontanelle, retinal and subhyaloid haemorrhages, and anaemia. These findings were not the result of a shaking injury but of a ruptured intracerebral arterial aneurysm.

With vigilance for child abuse and awareness of the possibility of cerebral injury from shaking increasing, alternative explanations of the characteristic clinical features of shaking may be overlooked. We describe a child in whom the initial impression of abusive shaking was false.

\section{Case report}

The girl was born uneventfully at term weighing $3300 \mathrm{~g}$, the first child to unmarried white parents living in poor circumstances. Her mother was aged 16 and her father 21 and unemployed. On the day of the child's admission at the age of 6 weeks, her father thought she was well when he fed her at $0600 \mathrm{~h}$. Four hours later her mother noticed a one minute episode of twitching of the left arm and hand. Similar episodes occurred at each feed of the day, but she sucked well and seemed normal between them. She screamed uncontrollably during her evening bath, with a further left sided seizure. At $2300 \mathrm{~h}$ she awoke screaming and looked pale and 
sweaty. Her father telephoned the family doctor and returned to bed but later accompanied her to hospital and said that he had recently bounced the baby, sleeping in her pram, down the few steps to the garden.

Shortly after admission she had several momentary episodes of left sided clonic seizures. She was afebrile but pale and irritable. The fontanelle was full. There were extensive bilateral retinal haemorrhages and a large right subhyaloid haemorrhage. There were no signs of direct injury or neglect, no cranial bruit, and normal femoral pulses. The head circumference was normal.

Her haemoglobin concentration was $8.5 \mathrm{~g} / \mathrm{dl}$. Other investigations with normal findings included white blood cell count and blood film, coagulation studies, platelets, and a full $x$ ray skeletal survey. Lumbar puncture showed moderataly blood stained cerebrospinal fluid with a xanthochromic supernatant and no evidence of infection.

A diagnosis was made of intracranial haemorrhage, probably resulting from shaking injury. She was transferred to the intensive care unit where an urgent computed tomogram of the brain showed a large intracerebral haematoma (Fig. 1). This was

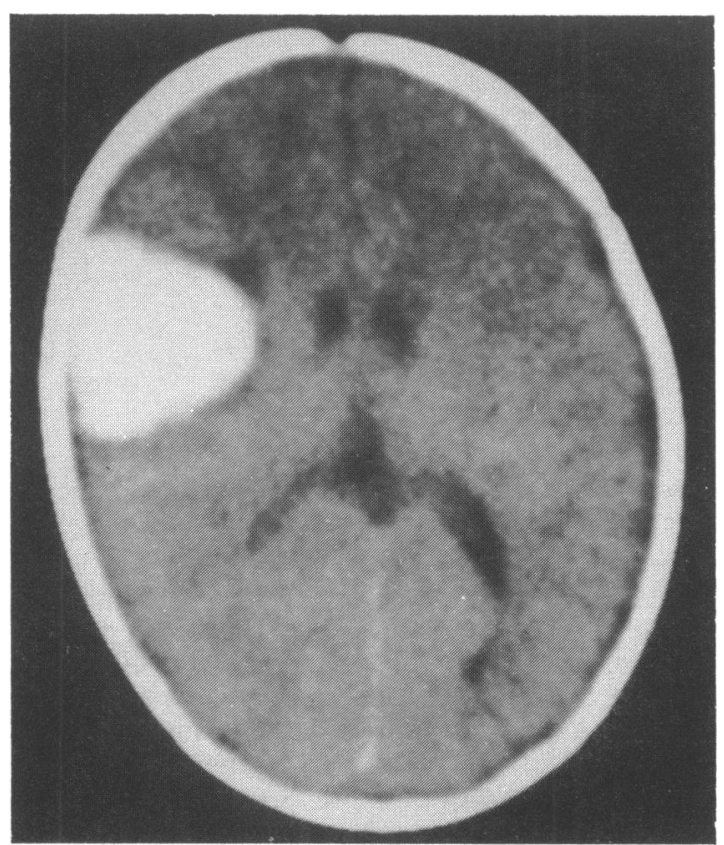

Fig. 1 Computed tomogram of the brain of our case without contrast on admission showing a localised haematoma in the right frontoparietal area. (Compare with Fig. 2.) considered to be incompatible with injury and to suggest spontaneous bleeding.

Her condition stabilised rapidly without further seizures. Transfemoral right common carotid angiography was performed 36 hours after admission. This showed an arterial aneurysm lying distally in an ascending frontal branch of the right middle cerebral artery. At craniotomy on the seventh hospital day the haematoma was evacuated and the aneurysm in its cavity removed. The only postoperative complication was a transient left sided weakness and at the age of 1 year she is clinically and developmentally normal.

\section{Discussion}

It is increasingly recognised that infants are particularly susceptible to cerebral injury by shaking. ${ }^{12}$ This may be accompanied by other clinical or radiological evidence of trauma but is often more subtle and difficult to establish. Retinal and subhyaloid haemorrhages are considered to be highly suggestive, if not pathognomonic, of the condition in infancy. ${ }^{12}$ We emphasise that they are not necessarily the hallmark of shaking and the presence of such haemorrhages should not become uncriti-

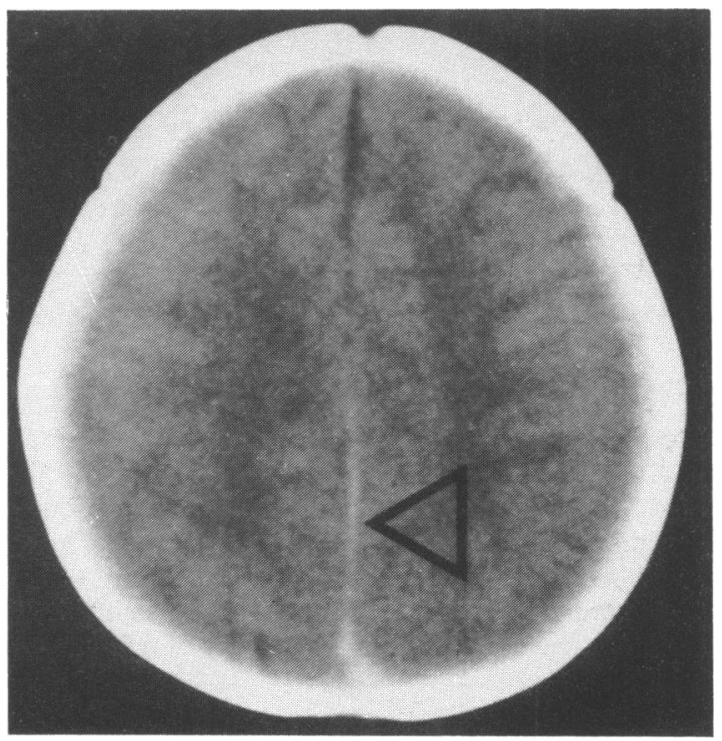

Fig. 2 Computed tomogram of the brain without contrast in an 8 week old child with fatal shaking injury, showing a posterior interhemispheric subdural haemorrhage (arrow), which contrasts with the normal density of the falx anteriorly. 
cally incorporated into 'standard practice' as the sine qua non of abuse. Equal open mindedness to the interpretation of social factors in such cases should be maintained until a definite diagnosis has been made.

Like any other haemorrhage, those in the optic fundus may be traumatic or spontaneous. Among the spontaneous causes, a bleeding diathesis should be considered. ${ }^{1}$ Diagnostic evaluation by computed tomography of the brain is also important. A localised intracerebral haematoma is most unlikely to be traumatic if there is no other evidence of parenchymal injury. Shaking may cause generalised brain contusion. ${ }^{3}$ Alternatively, a subdural haemorrhage may be induced and a posterior interhemispheric distribution is particularly characteristic of shaking injury (Fig. 2) ${ }^{4}$

Recognition of a subdural haemorrhage by aspiration through the anterior fontanelle should also be considered critically. Any intracranial haemorrhage may leak into the subarachnoid space and a subdural haematoma can develop if an aneurysm or arteriovenous malformation ruptures through the arachnoid mater. Such a finding has been described in a 3 month old child with an intracerebral aneurysm. ${ }^{5}$ Arteriovenous malformations may also occur within the meninges and so bleed directly into the subdural space. We can see little value in performing diagnostic subdural taps when access to computed tomography facilities are available.
We suggest that a computed tomogram of the brain should be considered urgently in the evaluation of cases of possible shaking injury or unexplained fundal haemorrhages. This should clarify the appropriate course to follow and prevent misinterpretation. A ruptured intracerebral arterial aneurysm may be eminently suitable for curative neurosurgery. ${ }^{6}$

We thank Dr Ian Holland for his neuroradiological expertise.

\section{References}

1 Caffey J. The whiplash shaken infant syndrome: manual shaking by the extremities with whiplash induced intracranial and intraoccular bleedings, linked with residual permanent brain damage and mental retardation. Pediatrics 1974:54:396-403.

2 Ludwig S, Warman M. Shaken baby syndrome: a review of 20 cases. Ann Emerg Med 1984;13:104-7.

${ }^{3}$ Ellison PH, Tsai FY, Largent JA. Computed tomography in child abuse and cerebral contusion. Pediatrics 1978;62:151-4

${ }^{4}$ Zimmerman RA, Bilaniuk LT, Bruce D, et al. Computed tomography of craniocerebral injury in the abused child. Radiology 1979;130:687-90.

5 Vapalanti PM, Schugk P, Tarkkanen L, Af-Bjorkesten G. Intracranial arterial aneurysm in a 3 month old infant. J Neurosurg 1969:30:169-71.

6 Crisostomo EA, Leaton E, Rosenblum EL. Features of intracranial aneurysms in infants and report of a case. Dev Med Child Neurol 1986;28:68-72.

Correspondence to Dr N McLellan, Consultant Paediatrician, Selly Oak Hospital, Raddlebarn Road, Birmingham B29 6JD, England.

Received 19 May 1986

\title{
Topical anaesthesia for venepuncture
}

\section{S CLARKE AND M RADFORD}

\author{
Department of Child Health, Southampton General Hospital
}

SUMMARY A topical anaesthetic cream was tested in a randomised, double blind, placebo controlled trial of 15 children. The severity of pain experienced during venepuncture was assessed, using visual analogue and verbal rating scales. The topical anaesthetic cream was found to be significantly superior to placebo using each form of assessment.

Venepuncture is probably the commonest procedure carried out on paediatric patients requiring medical treatment. Many children tolerate the procedure well, but for some it is a major ordeal. A topical preparation that could be applied without discomfort and alleviate the pain of venepuncture would be particularly useful for children receiving repeated venepunctures.

To penetrate intact skin a topical anaesthetic cream should contain local anaesthetic in high concentrations. This has hitherto been difficult to achieve because most anaesthetic bases are crystalline at room temperature and unstable in high concentrations. By mixing two anaesthetic bases, lignocaine and prilocaine, in equal proportions, an eutectic mixture is obtained that is liquid at room temperature. This mixture, known as EMLA (Eutectic Mixture of Local Anaesthetics), can be incorporated into an emulsion without first dissolving the bases in oil, making it possible to attain a 